Godina VIII | Broj 16 | Sveska 2/2020 | ISSN 2334-816X

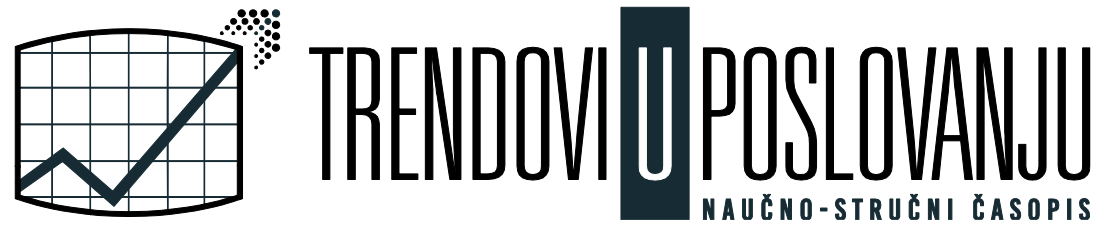

RAZUMEVANJE FAZA I CILJEVA PROCESA RAZVOJA KARIJERE U KONTEKSU USPEŠNOG UPRAVLJANJA KARIJEROM

\title{
UNDERSTANDING THE PHASES AND OBJECTIVES OF THE CAREER DEVELOPMENT PROCESS IN THE CONTEXT OF SUCCESSFUL CAREER MANAGEMENT
}

Ilić Đurđijana| Vojna akademija, Univerzitet odbrane u Beogradu, Ministarstvo odbrane, Beograd, Srbija I ilicdjina@yahoo.com

UDK: 005.966

005.336:005-051

COBISS.SR-ID 26779913

\section{Sažetak}

Osnovu kvalitetne organizacije čine pouzdani zaposleni koji su zadovoljni svojim poslom, spremni da uče i napreduju i time i sebi i organizaciji kontinuirano donose profit i progres. Temelj kvalitetne organizacije čine kvalitetna korporativna misija, razumna vizija organizacije, jasno postavljeni ciljevi i visok nivo kreativnosti i inovativnosti zaposlenih, usmereni na ispunjenje misije, vizije i ciljeva. Zaposleni koji nisu zadovoljni neće obavljati posao kako treba zbog čega organizacija trpi direktnu materijalnu štetu. Nezadovoljni zaposleni će želeti da napusti posao što govori u prilog tome da resursi ranije uloženi u tog zaposlenog nisu upotrebljeni u skladu sa misijom organizacije. Da bi organizacija uspešno poslovala i ostvarivala profit potrebno je neprekidno kontrolisati i održavati karijerni napredak i zadovoljstvo zaposlenih jer upravo na zadovoljnim i naprednim ljudskim resursima počiva njena uspešnost. Karijera podrazumeva napredovanje, progres, okupiranost profesijom i stabilnost koja se često razmatra i kao njen osnovni preduslov. Da je koncept razvoja karijere izrazito kompleksan govori činjenica da je proizveo veliki broj organizacionih fenomena koji se intenzivno proučavaju. Poznavanje, razumevanje i praćenje različitih faza procesa razvoja karijere, kao i brojnih i raznovrsnih ciljeva procesa razvoja karijere mogu bitno doprinositi uspešnom poslovanju organizacija.

\section{Abstract}

The basis of a quality organization consists of reliable employees who are satisfied with their work, ready to learn and progress, and thus continuously bring profit and progress to themselves and the organization. The foundation of a quality organization consists of a quality corporate mission, a reasonable vision of the organization, clearly set goals and a high level of creativity and innovation of employees, aimed at fulfilling the mission, vision and goals. Employees who are dissatisfied will not do the job properly, which is why the organization suffers direct material damage. Dissatisfied employees will want to leave the job, which speaks in favor of the fact that the resources previously invested in that employee were not used in accordance with the mission 
of the organization. In order for the organization to operate successfully and make profit, it is necessary to constantly control and maintain the career progress and satisfaction of employees, because its success is based on satisfied and advanced human resources. Career implies advancement, progress, occupation with the profession and stability, which is often considered as its basic precondition. That the concept of career development is extremely complex is shown by the fact that it has produced a large number of organizational phenomena that are intensively studied. Knowing, understanding and following the different stages of the career development process, as well as the numerous and diverse goals of the career development process can significantly contribute to the successful operation of organizations.

Ključne reči: upravljanje karijerom, razvoj karijere, faze karijere, ciljevi karijere.

Keywords: career management, career development, career stages, career goals.

JEL klasifikacija: E24

\section{Uvod}

Menadžment ljudskih resursa iz koje izvorno potiče i upravljanje karijerom oblast je nauke o organizaciji koja se bavi proučavanjem svih aspekata zaposlenosti u organizaciji. Imajući u vidu predmet izučavanja, ova naučna oblast se nije razvijala u izolaciji, već u širem kontekstu industrijskih promena i ekonomskog razvoja te predstavlja odgovor na dramatične i kontinuirane promene koje stvaraju civilizaciju novog svetskog poretka. [1] Razvoj karijere kao jednog od glavnih koncepata problematike ljudskih resursa više se ne posmatra zasebno, već se sagledava u kontekstu života i razvoja ličnosti u potpunosti, a ne samo ličnosti kao radnika. Uz prioritet koji se daje pojedincu, treba pomenuti i opštu korist koju razvoj karijere pruža organizaciji. [2] Snažan podsticaj i motiv za pojedince u organizaciji je mogućnost za napredovanje. Ova mogućnost ima značaja već u fazi regrutovanja ili privlačenja ljudi u organizaciju. „Politika unapređivanja zaposlenih i razvoja karijere treba da bude trajna aktivnost sektora za ljudske resurse, od kojeg se očekuje da kreira objektivne kriterijume za napredovanje i pomeranje zaposlenih sa nisko rangiranih na više i visoko rangirana radna mesta, kako ovo pomeranje ne bi bilo stvar dobre volje pojedinca i ličnih simpatija, već standard koji se, kada se steknu uslovi, automatski primenjuje". [3] Uzimajući u obzir pravilno poimanje značaja razvoja karijere za svakog pojedinca, ali i za organizaciju, neophodno je bliže odrediti pojam karijere, a zatim i faze i ciljeve procesa razvoja karijere kako sa aspekta pojedinca, tako i sa aspekta organizacije.

\section{Pojam karijere}

Pojam karijere se tokom vremena menjao. Reč karijera potiče od latinske reči carrusšto u prevodu na srpski jezik znači prevozno sredstvo, i via carraria što u prevodu na srpski jezik znači kolovoz, odnosno put kojim se neko kreće. [4] Može se zaključiti da reč karijera podrazumeva kretanje, odnosno put kojim se neko kreće kako bi dostigao određeni cilj.

Postoje mnogobrojne definicije karijere. „Karijera je zanimanje pojedinca koje mu omogućuje da ostvari napredovanje i satisfakciju u svom radu”. [5] „Karijera je sukcesija povezanih poslova raspoređenih po hijerarhijskom principu kroz koje se pojedinac kreće po manje ili više predvidivom redosledu". [6] "Karijera predstavlja individualno percipiranu sekvenciju stavova i ponašanja poveznaih sa iskustvom i aktivnostima vezanim za rad u toku života osobe". [7] "Karijera je evoluirajuća sekvencija radnog iskustva osobe tokom vremena". [8] "Karijera je skup iskustava povezanih sa radom koja se protežu kroz čitav život osobe". [9] Iz prikazanih definicija karijere, može se zaključiti da karijera ne predstavlja samo skup aktivnosti koje pojedinac obavlja, već pravac kojim se kreće i na kojem ostvaruje, kako profesionalni, tako i personalni razvoj.

Prilikom određenja pojma karijere potrebno je pridržavati se određenih prepozicija. To su: [10] definicija karijere treba da bude takva da se odnosi na sve zaposlene i sve organizacije; treba 
naglasiti značaj vremenske dimenzije, odnosno razvojni proces kao ključni faktor u odnosima između pojedinca i organizacije; karijeru treba posmatrati kao multidisciplinarni koncept koji uključuje više disciplina, kao što su psihologija, sociologija, antropologija, političke nauke i ekonomija i, karijeru treba posmatrati iz subjektivne ali i objektivne perspektive.

\section{Sličnosti i razlike između pojmova posla i karijere}

Pojmovi posao i karijera imaju mnogo međusobnih sličnosti, ali i razlika. Tako, sličnost između pojmova posla i karijere je ta da se prilikom obavljanja aktivnosti kao dela rutine profesije pojedinca, troši njegova bioenergija koja se isplatom zarade, kasnije, reprodukuje. Međutim, između posla i karijere postoji mnogo više razlika. Tako, razlike između pojmova posla i karijere mogu biti zavisne od: stava pojedinca, stepena emocionalnog investiranja pojedinca i njegove spremnosti da investira u svoj dalji razvoj. Stav pojedinca o poslu i karijeri je od izuzetnog značaja. Naime, ukoliko pojedinac ima stav da aktivnosti koje obavlja na određenom radnom mestu predstavljaju aktivnosti koje treba obaviti samo da bi se ostvarila zarada, to predstavlja posao. Ukoliko pojedinac ima stav da aktivnosti koje obavlja vidi kao jednu od sekvencija u njegovom daljem profesionalnom razvoju i napredovanju, to predstavlja karijeru. [11]

Stepen emocionalnog investiranja pojedinca podrazumeva pitanje da li zaposleni pojedinac svoj trenutni posao posmatra kao deo svoje karijere ili samo kao skup aktivnosti koje treba obaviti. „Pod emocionalnim investiranjem podrazumeva se stepen do koga je pojedincima važan posao koji obavljaju, odnosno ovaj kriterijum odslikava kakva je njihova unutrašnja motivacija povezana sa radom". [10] Kako bi zaposleni posao koji obavlja smatrao karijerom, potrebno je da oseća emocionalnu povezanost sa tim što radi, odnosno da to što radi, radi sa razlogom.

Spremnost pojedinca da investira u svoj dalji razvoj je takođe od velike važnosti za razlikovanje posla od karijere. Pojedinac će videti sebe kao osobu koja ima karijeru ukoliko ga posao koji obavlja vidi kao nešto što ga vodi daljem razvoju i napredovanju. Pojedinac će investirati u svoj dalji razvoj ukoliko u organizaciji postoji mogućnost napredovanja i tada će imati psihološko osećanje uspeha $\mathrm{i}$ ispunjenosti.

Usvajanje koncepta karijere umesto koncepta posla od strane zaposlenih ide u prilog i samim organizacijama, i to iz dva razloga. Prvi razlog je dinamično i turbulentno poslovno okruženje koje organizacijama nameće potrebu za zaposlenima koji nisu samo neposredni izvršioci radnih zadataka, bez želje da napreduju u svojoj profesiji, nego zaposleni koji su spremni na konstantna učenja i prilagođavanja, što koncept karijere i podrazumeva. Drugi razlog je što nastojanje organizacije da zaposleni ostvare napredak i progres u tome što se radi, doprinosi i uspehu organizacija, jer su organizacije uspešne onoliko koliko su uspešni i zaposleni koji ih čine. [12]

Razvoj same organizacije zavisi upravo od opisanih stavova zaposlenih. Neophodno je da menadžment ljudskih resursa u organizacijama kreira organizacionu kulturu i ponašanje u kojoj će se vrednovati znanje, posvećenost i razvoj zaposlenih. Samo na taj način organizacija može dobiti zaposlene koji usvajaju koncept karijere umesto koncepta posla i doprineti razvoju organizacije u budućnosti.

\section{Značaj razvoja karijere}

Razvoj karijere se više ne posmatra zasebno, već se sagledava u kontekstu života i razvoja ličnosti u potpunosti, a ne samo ličnosti kao radnika. Razvoj karijere je iskustvo pojedinca (što se ponekada naziva internom karijerom) i nije nužno vezano za samo jednu organizaciju. Ovo takođe znači da je odgovornost za upravljanje karijerom na pojedincu, iako organizacija može imati ključnu ulogu u pružanju pomoći i podrške. 
Primarni cilj razvoja karijere je ostvarivanje aktuelnih i budućih potreba organizacije i pojedinca na poslu, što sve više podrazumeva razvoj mogućnosti zaposlenja, odnosno razvoj sposobnosti za zapošljavanje. „Postaje sve teže izdvojiti razvoj karijere od opšte obuke i razvoja. Tako se nameće pitanje važnosti samostalnog razvoja. Uspeh u karijeri se posmatra očima pojedinca i može se definisati kao zadovoljstvo karijerom kroz ostvarivanje ličnih ciljeva u vezi sa poslom, a u okviru doprinosa organizaciji". [13]

Uz prioritet koji se daje pojedincu, treba pomenuti i opštu korist koju razvoj karijere pruža organizaciji. Tako, razvoj karijere pojedinca: čini da organizacija bude atraktivnija za potencijalne radike; jača imidž organizacije time što pokazuje da ume da prepozna potrebe zaposlenih; velika je verovatnoća da će podstaći posvećenost zaposlenih i smanjiti obrt osoblja; velika je verovatnoća da će podstaći motivaciju i poboljšati rezultate rada jer su zaposleni u mogućnosti da vide kretanje i napredovanje u svom poslu i, što je verovatno najvažnije, izvlači sav potencijal radne snage. Pre nego što se razmotre teorije razvoja karijere, neophodno je razmotriti neke od osnovnih koncepata koji se odnose na karijeru.

\section{Faze razvoja karijere}

Mnogi autori su pokušali da izdvoje idealne faze uspešne karijere prema starosnim granicama za svaku fazu. Tako, Edgar Čein (Edgar Schein) nudi devet faza ciklusa karijere. [14] Pet faza karijere predlaže autor Donald Super (Donald Super). [15] Ipak, u ovom delu rada biće razmotreno pet faza koju navode Džefri Grinhaus (Jeffrey H. Greenhaus) i Džerard Kalanan (Gerrard A. Callanan), a to su: [15] izbor zanimanja - priprema za posao; ulazak u organizaciju; rana karijera - početak i ostvarenje; srednja karijera i pozna karijera. Može se reći da je malo karijera koje prate tako idealizovanu formu, pa čak i istorijski gledano, takva forma se nije odnosila na sve zaposlene. Međutim, pristup po fazama daje koristan okvir za razumevanje iskustava tokom karijere, ukoliko se koristi kao sredstvo za razumevanje karijera, a ne kao normativni model.

Prva faza, izbor zanimanja - priprema za posao može trajati otprilike do 25 . godine ili se može iznova javiti kod osoba koje kasnije tokom života žele da promene karijeru. Ona podrazumeva razvoj sopstvenog profesionalnog imidža. Tokom ove faze je najbitnije uskladiti odnos između snaga i slabosti, vrednosti i željenog stila života pojedinca sa zahtevima i koristima niza profesija. Jedan od problema koji se mogu javiti u ovoj fazi jeste nedostatak svesti o samom sebi. Mnogo je testova koji pojedincu pomažu da ustanovi sopstvena interesovanja, ali oni mogu dati samo jedan deo slike i moraju biti dopunjeni strukturiranim vežbama koje pomažu ljudima da sami sebe sagledaju iz različitih perspektiva. Ostali problemi se odnose na ograničenja koje pojedinci imaju zbog društvenih, kulturnih, rasnih osobenosti ili karakteristika posla. Iako se koriste modeli uloga da bi se ustanovila potencijalna zanimanja, što proširuje dijapazon mogućnosti o kojima se razmišlja, taj proces ih može i suziti. Drugi problem u ovoj fazi je dobijanje autentičnih informacija o karijeri koje se razlikuju od onih koje se dobijaju od porodice i prijatelja.

Druga faza se preklapa sa prvom fazom koja može trajati obično između 18. i 25. godine. Ulazak u organizaciju podrazumeva da pojedinac nalazi posao, koji odgovara njegovom profesionalnom imidžu, kao i početak rada. Problemi se u ovoj fazi koncentrišu na preciznost informacija koje organizacija pruža, tako da se kada pojedinac počne da radi očekivanja i stvarnost mogu veoma razlikovati. Osobe koje se bave regrutovanjem razumljivo „prodaju" svoju organizaciju, kao i posao potencijalnom zaposlenom, naglašavajući najbolje, a zanemarujući loše strane. Prijavljeni često zaboravljaju da provere svoje pretpostavke tako što će postaviti pitanje o određenim informacijama koje su im zaista potrebne. Takođe, škole, koledži i univerziteti su do nedavno pripremali učenike za tehničke zahteve posla, ignorišući ostale sposobnosti koje će im biti potrebne, kao što su sposobnosti komunikacije, uticanja na druge i one koji se odnose na organizacionu politiku. Kako bi se potpomogao ulazak u organizaciju neophodno je realističnije regrutovanje. To podrazumeva da menadžment ljudskih resursa u organizaciji dâ kandidatima o svakom radnom mestu i samoj organizaciji što realističnije stanje. 
Treća faza, odnosno rana krijera - početak i ostvarenja traje između 25. i 40. godine. Početak podrazumeva uklapanje u organizaciju i razumevanje "kako se stvari u njoj obavljaju". Detaljni programi uvođenja u posao jesu važni, ali je još važnije da se novom radniku dâ pravi posao i pred njega stave izazovi, a ne da "tumara" od odeljenja do odeljenja bez jasnog cilja (što se često može naći u šemama obuke). Povratne informacije i podrška nadređenog menadžera su, takođe, veoma bitne. Ostvarenja u ovoj fazi podrazumevaju pokazivanje kompetentnosti i sticanje veće odgovornosti i autoriteta. Pristup mogućnostima za razvoj karijere postaje bitan upravo u ovoj fazi. Ukoliko organizacija ima strukturiran pristup razvoju karijere (to ne mora nužno biti hijerarhijsko napredovanje), što podrazumeva lestvice, putanje ili matrice karijere, onda to omogućava razvoj u okviru posla, unapređenja i šira pomeranja. Povratne informacije su i dalje važne, kao i mogućnosti i podrška za dalje kretanje i planiranje karijere. Organizacije većinom najveću podršku daju zaposlenima koji imaju "visoke ciljeve", koji se posmatraju kao budući viši menadžment i mogu biti uključeni u programe „brzog kretanja".

Četvrta faza je srednja karijera koja obično dolazi između 40. i 55. godine, a može podrazumevati dalji razvoj i napredovanje ili zadržavanje postojećeg statusa. U oba slučaja prati je neka forma ponovne evaluacije karijere i životnog smera, ali je broj onih koji će doživeti pad u ovoj fazi manji. Ukoliko osoba nastavi da napreduje, organizaciona podrška ostaje bitna. Neki ljudi, koji su dostigli vrhunac u karijeri, misliće da su neuspešni. Međutim, organizaciona podrška u ovakvim slučajevima mora uključivati lateralne staze karijere, proširenje posla, postavljanje na mesto mentora, dalje obučavanje kako bi se išlo u korak s vremenom, kao i korišćenje fleksibilnog sistema nagrađivanja.

Peta faza tzv. pozna karijera, podrazumeva zadatak organizacije da podstiče ljude da nastave sa ostvarivanjem dobrih rezultata. To je posebno važno jer se pojedini sektori suočavaju sa manjkom sposobnosti, a javljaju se inicijative nekih kompanija da se pojedincima dozvoli da rade i nakon što se penzionišu. „Uprkos stereotipima koji starije ljude definišu kao spore i manje sposobne da uče, ovi radnici će dobro obavljati posao ukoliko organizacije veruju da će im oni dobro doći i ukoliko se prema njima odnose u skladu sa tim. Raspoloživost fleksibilnih radnih formi, jasni standardi rada, stalno obučavanje i izbegavanje diskriminacije su veoma bitni u ovoj fazi, zajedno sa pripremom za penziju". [17]

\section{Ciljevi karijere}

Ciljevi karijere objašnjavaju način na koji svaki pojedinac odlučuje o svojoj karijeri. Daleko su širi od motivacije, što podrazumeva svest o sopstvenim talentima i sposobnostima, svest o sopstvenim motivima i potrebama i svest o sopstvenim stavovima i vrednostima.

Čovekova svest o ovim oblastima proizilazi iz neposrednog radnog iskustva, iz uspeha, preispitivanja i povratnih informacija. Zaključci koje ljudi donose podjednako pokreću i usporavaju razvoj buduće karijere. Kroz ciljeve karijere vidi se celokupan prikaz ličnosti, na osnovu interakcije pomenutih faktora. Ciljevi karijere mogu otkriti stepen stabilnosti ličnosti koji je uticao na izbore u prošlosti i koji će verovatno uticati na izbore u budućnosti. Problematičan aspekt ciljeva karijere jeste tačnost sopstvene percepcije, kao i pitanje šta se dešava u periodu srednje karijere onima koji osećaju da se njihovi stavovi i vrednosti menjaju. Neophodno je da svi ljudi uvide šta su njihovi ciljevi kako bi bili sigurni da postupaju ispravno, a takođe je neophodno da prihvate da postoje i druge stvari koje će im biti potrebne i dalje, čak i ako naprave promene u karijeri.

Postoji devet ciljeva karijere. [18] To su: tehnička/funkcionalna kompetentnost, menadžerska kompetentnost, sigurnost i stabilnost, kreativnost, autonomija i nezavisnost, osnovni identitet, pružanje usluga drugima, moć, uticaj i kontrola i raznolikost.

Osobe koje imaju cilj da steknu tehničku odnosno funkcionalnu kompetentnost su zainteresovane za tehničku stranu i kompetentno obavljanje posla. Njih obično ne zanima sâm menadžment jer više vole da primenjuju svoje tehničke sposobnosti. Oni će, ipak, biti spremni da preuzmu menadžerske odgovornosti u svojoj oblasti. Osobama koje sebi za cilj karijere postave 
menadžersku kompetentost primena menadžerskih sposobnosti predstavlja vrhunac karijere, a tehnički i funkcionalni poslovi samo su način da se do njega dođe. Ove osobe većinom završavaju na opštim menadžerskim poslovima i imaju dve ključne kompetentnosti, a to su analitička (za rešavanje problema koje karakterišu nepotpune informacije i nepoznanice) i interpersonalna (za uticaj i kontrolu i emocionalnu stabilnost, uz sposobnost da ih kriza stimuliše, a ne parališe).

Sigurnost i stabilnost su osobine svojstvene osobama kojima je cilj karijere da budu spremni da rade ono što organizacija od njih zahteva da bi osigurali posao i trenutne i buduće koristi koje on donosi. Ukoliko im se pruži izbor većina njih će odlučiti da ostane u jednoj organizaciji celog života, bez obzira na to što imaju i druge mogućnosti, kao što je da ostanu u istoj geografskoj oblasti, ali da ne rade samo za jednog poslodavca, kao i pravljenje odvojenih finansijskih zaliha za budućnost. Zbog toga što ne "jure" karijeru i ne trude se da napreduju hijerahijski, oni sa ovakvim ciljem karijere često osećaju da nisu uspešni i teško prihvataju sopstveni kriterijum za uspeh u karijeri. Ova grupa je sklonija integrisanju karijere sa porodičnim životom.

Osobe kojima je kreativnost cilj karijere imaju potrebu da izgrade nešto novo. Njih pokreće želja da prošire svoje delovanje, da se uključe u nove poduhvate i projekte, a mogu se opisati kao preduzetnička grupa. Ukoliko se njihov poduhvat pretvori u unosan posao, dosadiće im da ga rade i uglavnom će taj deo posla prepustiti drugima. Želja za oslobađanjem od organizacionih stega pri primeni tehničke/funkcionalne kompetentnosti, pokreće ljude kojima je to cilj karijere. Oni uglavnom nalaze da je organizacioni život restriktivan i da se upliće u njihov život, pa više vole svoj mir i sopstveni stil rada. Obično rade sami ili u malim firmama. Konsultanti, pisci i predavači su tipične uloge koje ova grupa preuzima. Osobe kojima je osnovni identitet cilj karijere pokreće potreba da ostvare i zadrže identitet u poslu koji obavljaju. Oni se najčešće nalaze na nižim pozicijama u kojima je njihova uloga i vizuelno prikazana, primera radi da nose bedž ili uniformu. Na ovaj način je njihova uloga definisana spolja, a neki od njih mogu želeti da se vežu za prestižnog poslodavca.

Pokretačka snaga u pružanju usluga drugima je potreba da se pomaže često primenom interpersonalne kompetentnosti ili drugih veština. Potreba je ne samo da se takva kompetentnost primenjuje kao krajnja sama po sebi, već se njena svrha ogleda u pružanju pomoći drugima. Tipični primeri cilja karijere kroz koji se pružaju usluge drugima imaju učitelji i doktori. Moć, uticaj i kontrola kao ciljevi karijere se mogu odvojiti od menadžerskog cilja ili se mogu posmatrati kao njegov deo. Ljudi koje pokreće ovakav cilj karijere mogu se baviti politikom, predavanjem, medicinom ili religijom, jer su to oblasti u kojima mogu da stvore uticaj i kontrolu nad drugima.

Ljudi tragaju za raznolikošću iz nekoliko razloga. Ovakav cilj karijere može biti relevantan za one koji su višestruko nagrađeni, koji vrednuju fleksibilnost ili im sve jako brzi dosadi. Treba pomenuti da postoje i drugi oblici karijere. Tako, postoje četiri oblika karijere pojedinca: [19] „prelazne" karijere (kada pojedinac često menja posao i ne pokazuje stabilnost), karijere koje su u "stanju mirovanja" (kada se izbor zanimanja obavi veoma rano i kada se ne menja), "linearne karijere" (kada se oblast rada bira rano, a pomeranje naviše je imperativ) i "spiralne" karijere (kada se pojedinci razvijaju u jednoj oblasti neko vreme, a zatim prelaze na drugu oblast ili oblasti). Ovi okviri su na neki način odeleli vremenu od teorije o fazama karijere.

\section{Zaključak}

Karijera je interes, potreba i očekivanje pojedinca koje mu omogućuje da ostvari napredovanje i satisfakciju u svom radu. Potrebe prakse, zahtevi vremena i savremeni društveni trendovi usmeravaju odgovornost za upravljanje karijerom sve više ka pojedincu, iako organizacija može imati ključnu ulogu u pružanju pomoći i podrške. Primarni cilj razvoja karijere je ostvarivanje aktuelnih i budućih potreba organizacije i pojedinca na poslu, što sve više podrazumeva razvoj mogućnosti zaposlenja, odnosno razvoj sposobnosti za zapošljavanje. Uz prioritet koji se daje pojedincu, treba pomenuti i opštu korist koju razvoj karijere pruža organizaciji. Upravljanje karijerom danas se odnosi na skup najrazličitijih aktivnosti koje imaju za cilj da omoguće realizaciju svih planiranih akcija u pravcu razvoja željene karijere pojedinca. Kroz ovaj proces zaposleni se 
usavršavaju, stiču nova znanja i veštine, a postojeće dovode do savršenstva, što u krajnjoj instanci ima značaj i za rezultate poslovanja organizacije jer stručniji i sposobniji zaposleni mogu mnogo više da ponude i doprinesu organizaciji od onih koji to nisu. S tim u vezi, mobilnost zaposlenih u savremenim uslovima poslovanja i njihova brza adaptabilnost sve su češća pojava. Zadovoljstvo zaposlenih implicira zadovoljstvo organizacije i obrnuto te isto treba shvatiti kao kontinualni proces na kome treba raditi stalno. Odluci o napuštanju organizacije uvek prethodi period nezadovoljstva i izostanaka sa posla a onima koji odlučuju je potrebno na vreme dostaviti tačne informacije [20] bez kojih odlučivanje neće biti realno ni potpuno. Osim toga, nezadovoljstvo poslom ne utiče samo na neproduktivnost već i na neke druge pojave u organizaciji kao što su odsustvovanje sa posla (apsentizam) i fluktuacija. [21] Usklađivanje ponašanja pojedinaca sa organizacionim ciljevima jeste kritički problem upravljanja. I ekonomisti i psiholozi su istakli da se ljudsko ponašanje ne može često objasniti preko standardnih modela baziranih na racionalnim, dobro informisanim i optimizirajućim subjektima/predmetima. Ljudi nisu mehanički uređaji već kreativna bića koja kreativno odgovaraju kako na prilike koje okruženje postavlja pred njih, tako i na ograničenja koja ih sprečavaju da čine ono sto žele. [22] Stoga, značaj koji upravljanje karijerom i razvoj karijere imaju za sve učesnike u privrednoj aktivnosti je nemerljiv pa se zato ovom procesu posvećuje velika pažnja u svim organizacijama koje žele dobro da posluju, da budu uspešne i da ostvaruju dugoročne poslovne uspehe, kako na individualnom tako i na organizacionom nivou.

\section{Bibliografija}

[1] Ilić Đ., Janjić I., Ilić S. „Upravljanje karijerom putem karijernog savetovanja”, naučno - stručni časopis "Trendovi u poslovanju", sves. 2, br. 14, 2019. g., Visoka poslovna škola strukovnih studija „Prof. dr Radomir Bojković" Kruševac, ISSN 2334-816X UDK:005.966005.942, str. 37

[2] Ilić Đ., Andrejić, M., Dragović N., "Menadžment ljudskih resursa", Zbornik radova sa 20. DQM Međunarodne konferencije UPRAVLJANJE KVALITETOM I POUZDANOŠĆU ICDQM-2017, Istraživački centar za upravljanje kvalitetom i pouzdanošću - DQM, Prijevor, jun 2017. g., str. 322

[3] Petković, M. (2011), Organizaciono ponašanje sa menadžmentom ljudskih resursa, Centar za izdavačku delatnost, Ekonomski fakultet, Beograd, str. 232

[4] McCash, Ph, (2008), Career studies handbook: career development learning in practice, The Higher Education Academy, Heslington, London, стр. 9

[5] Brewer, J, M. (1922), The Vocational - Guidance Movement, MacMillan, New York, y Brent, G. (2006), Young People's Perception of Career Success in Aotearoa//New Zeland: an Exploatory Analysis, Albany and Palmerston North, Labour Market Dynamic Research Programme, Research Report, No. 3, стр. 7

[6] Wilkensky, H. L. (1961), Orderly Careers and Social Participation: The Impact of Work History on Social Integration in the Middle Mass, American Sociological Review, 26(4), стр. 523

[7] Hall, D. T. (1976), Careers in Organizations, Pacific Palisades, CA, Goodyear, y Hall, D. T. (2004), The protean career: A quarter-century journey, Journal of Vocational Behavior, 65, стр. 1

[8] Arthur, M. B., Hall, D. T., Lawrence, B. S. (1989), Handbook of career theory, Cambridge University Press, y Inkson, K. (2007), Understanding Careers, The Methaphors of Working Lives, SAGE Publications, Thousand Oaks, стр. 3

[9] Greenhaus, H. J., Callanan, A. G., Godhalk, M. V. (2000), Career Management, The Dryden Press, Harcourt Publishers, стр. 9

[10] Đorđević, B. (2012), Uspeh u karijeri, Ekonomski fakultet, Niš, str. 4, 8

[11] Pixely, J. (2003), Presentation at Academic Work-Life Conference, Orlando, FL., y Harrington, B., Hall, D. T. (2000), Career Management\&Work-Life Integration, Using Self-Assessmant to Navigate Contemporary Careers, SAGE Publications, стр. 10 
[12] Bahtijarević-Šiber, F. (1999), Menadžment ljudskih potencijala, Golden marketing, Zagreb, str. 828

[13] Walton, J. (1999), Strategic Human Resource Development, Financial Times Prentice Hall, Harlow, стр. 119

[14] Schein, E. (1978), Career Dynamics: Matching individual and organizational needs, Reading, Mass, Addison-Wesly, cтр. 21-22

[15] Super, D. E. (1980), A life span, life space approach to career development, Journal of Vocational Behaviour, Vol. 16, стр. 282-298

[16] Greenhaus, J. H., Callanan, G. A. (1994), Career Management, Dryden Press, London, стр. 256-264

[17] Mayo, A. (1991), Managing Careers: strategies for organizations, IPM, London, u Torrington, D., Hall, L., Taylor, S. (2004), Menadžment ljudskih resursa, Data status, Beograd, str. 444-445

[18] Schein, E. (1978), Career Dynamics: Matching individual and organizational needs, Reading, Mass, Addison-Wesly, u Torrington, D., Hall, L., Taylor, S. (2004), Menadžment ljudskih resursa, Data status, Beograd, str. 446

[19] Driver, M. (1982), Career concepts - a new approach, Prentice Hall, New Jersey, y Torrington, D., Hall, L., Taylor, S. (2004), Менаџмент људских ресурса, Дата статус, Београд, стр. 448

[20] Anđelić S., Rastić A., Ilić D., Analysis od Trade Condition in Ras Region, International Review, 2017., 2[2], pp. 143-148

[21] Janjić I., Ilić Đ., Zadovoljstvo poslom u fazama karijere zaposlenih, Zbornik radova sa treće naučno - stručne konferencije sa međunarodnim učešćem „Trendovi u poslovanju", održane 16. maja 2019. godine, Visoka poslovna škola strukovnih studija "Prof. dr Radomir Bojković" Kruševac, str. 193 - 198

[22] Ilić S., Ilić Đ., „Važnost analize posla kao aktivnosti menadžmenta ljudskih resursa”, Zbornik radova sa četvrte naučno - stručne konferencije sa međunarodnim učešćem „Trendovi u poslovanju", održane 24. septembra 2020. godine, Visoka poslovna škola strukovnih studija „Prof. dr Radomir Bojković" Kruševac, str. 143 - 150 